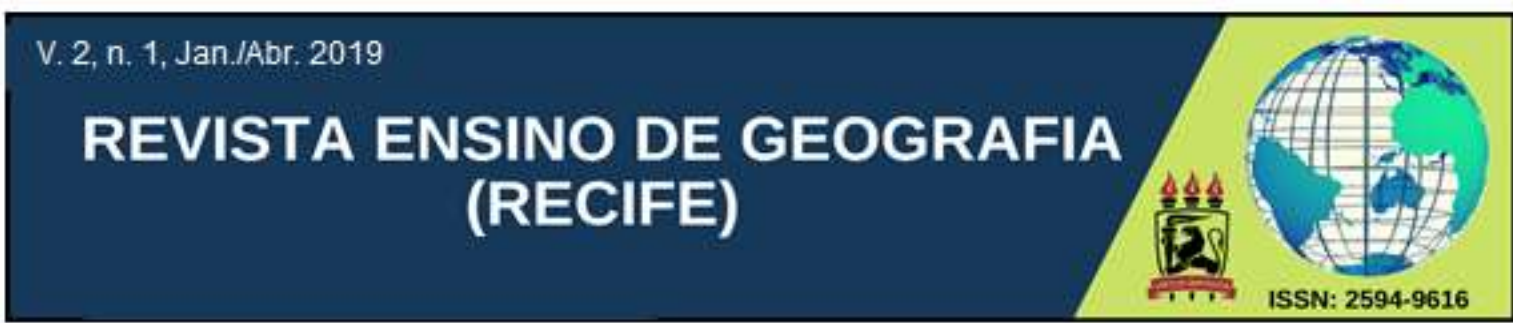

\title{
EXPERIMENTOS COMO RECURSOS DIDÁTICOS PARA EDUCAÇÃO EM SOLOS NO ENSINO DE GEOGRAFIA
}

\author{
Jean Oliveira Campos \\ Pedagogo, Graduando do curso de Licenciatura em Geografia pela UEPB \\ jeannolliveira@gmail.com \\ ORCID iD: https://orcid.org/0000-0003-2121-9688 \\ Jardênio de Oliveira Marinho \\ Graduando do curso de Licenciatura Plena em Geografia da UEPB \\ jardeniomarinho@gmail.com \\ ORCID iD: https://orcid.org/0000-0002-2554-9353 \\ Lediam Rodrigues Lopes Ramos Reinaldo \\ Engenheira Agrônoma, Mestre em Solos e Nutrição de Plantas, Doutora em Recursos \\ Naturais, Docente do curso de Licenciatura em Geografia da UEPB \\ lediamrodrigues@gmail.com \\ ORCID iD: https://orcid.org/0000-0001-6618-9860
}

Artigo recebido em 22/04/2019 e aceito em 06/06/2019

\begin{abstract}
RESUMO: O solo é um recurso natural finito, constituído por minerais, matéria orgânica, água e ar. Indispensável à manutenção da biodiversidade na superfície terrestre. Devido à sua importância, o ensino do solo deve fornecer aportes teóricos e práticos que permitam ao educando compreender seus processos de origem e desenvolvimento, funções e propriedades, buscando promover a conscientização ambiental. Entretanto, nas aulas de Geografia, os solos não têm recebido a devida importância, as lacunas na formação docente e a ausência de recursos didáticos significativos têm resultado em abordagens superficiais e descontextualizadas do conteúdo. Diante do exposto, o presente artigo tem como objetivo promover a experimentação com solos como recurso didático para a abordagem do conteúdo na Educação Básica. Para tanto, foram discutidas e apontadas abordagens didáticas e desenvolvidos experimentos com solos com duas turmas do componente curricular Pedologia, do curso de licenciatura em Geografia, da Universidade Estadual da Paraíba. Os experimentos se evidenciaram facilitadores da aprendizagem em solos, na medida em que promoveram a construção dos principais dos conceitos e possibilitaram explorar novas possibilidades no processo de ensino-aprendizagem dos solos. Dessa forma, proporcionando abordagens mais concretas e significativas por parte dos futuros professores no ensino Fundamental e Médio.
\end{abstract}

Palavras-chave: Ensino de Geografia; Ensino do Solo; Recurso didático. 


\title{
EXPERIMENTS AS DIDACTIC RESOURCES FOR SOIL EDUCATION IN GEOGRAPHY EDUCATION
}

\begin{abstract}
Soil is a finite natural resource, consisting of minerals, organic matter, water and air. Indispensable to terrestrial biodiversity. Due to its importance, soil education should provide theoretical and practical contributions that enable the learner to understand their origin, development, functions and properties. However, in the Geography classes, the soils have not received the importance, the gaps in teacher training and the absence of significant didactic resources have resulted in superficial approaches and decontextualized content. In view of the above, this article aims to promote soil experimentation as a didactic resource for the content approach in basic education. To do so, didactic approaches and experiments with soils with two groups of the Pedology curricular component of the undergraduate course in Geography of the State University of Paraíba were discussed and pointed out. The experiments proved to be facilitators of learning in soils, insofar as they promoted the construction of the main concepts, practical approaches, and made it possible to explore new possibilities in the teaching-learning process of the soils. In this way, providing more concrete and meaningful approaches on the part of the future teachers in primary and secondary education.
\end{abstract}

Keywords: Geography Teaching; Soil Education; Didactic resource.

\section{INTRODUÇÃO}

O solo é um corpo natural finito, constituído por minerais, matéria orgânica, água e ar, indispensável à sobrevivência e manutenção da diversidade biológica na superfície terrestre. Portanto, o ensino do solo de faz de fundamental importância para conscientização ambiental visando promover seu adequado manejo e conservação. Durante a Educação Básica o ensino do solo é conferido aos componentes curriculares de Ciências e Geografia, e mais precisamente à Geografia por abordar em seus conteúdos as formas de apropriação e ocupação do espaço geográfico. No entanto, na maioria das vezes o conteúdo de solos é visto como difícil de ser ensinado, seja pela falta de domínio do professor sobre o conteúdo, seja pela ausência de suportes que permitam ao professor ministrar o conteúdo com maior propriedade, a exemplo dos recursos didáticos.

Nas aulas de Geografia o solo costuma ser abordado apenas de forma sumária, sem a devida importância. Cenário que ocorre em virtude do domínio inadequado dos conteúdos que compõem a chamada Geografia Física, evidenciando nesse contexto, uma lacuna na formação docente. O conteúdo de solo no livro didático de Geografia, na maioria das vezes é apresentado em poucas páginas e descontextualizado da realidade do educando, o que dificulta a construção de uma aprendizagem significativa sobre o solo.

Segundo Lima (2005), o solo sendo um componente dos ecossistemas naturais e antropizados, exerce influência sobre o ambiente e as sociedades, e seu estudo justifica-se pela função de sustentáculo para as atividades humanas no espaço rural e urbano, bem como para os ecossistemas nele instalados. Destaca-se entre as suas funções a produção de alimentos, fibras, sustentação de edifícios, cidades e manutenção dos sistemas aquáticos e 
terrestres. Diante desse cenário, o ensino do solo cumpre a função de contribuir para conscientização em relação à importância do solo no ambiente, além de evidenciar sua condição de fragilidade (FONTES; MUGGLER, 1999). Lima, Andrade e Fortuna (2016) apontam que o ensino do solo deve ocorre de forma participativa e com apoio de metodologias e recursos didáticos que possibilitem a construção de uma aprendizagem significativa, permitindo ao educando analisar o solo de forma integrada nos aspectos físicos e humanos, objetivando conscientizar o educando sobre sua importância para o ambiente e para as necessidades humanas.

Utilizar amostras de solo e as feições morfológicas deste como recurso didático nas aulas de Geografia constitui uma importante experiência prática para a construção do conhecimento em solos. As aulas práticas permitem que o ensino do solo se torne real e significativo para o educando, em vista que muitas vezes o conceito de solo é abstrato e pode dificultar a construção do conhecimento (GOULART; SILVA; WABER, 2016). Quando em contato com este recurso natural, o educando pode interagir, apresentar suas dúvidas e questionamentos, analisar suas feições e composição, conferindo assim, maior significação ao processo de aprendizagem do conteúdo.

A realização de atividades práticas constitui um importante meio de aprendizagem no componente curricular de Geografia, permitindo uma maior aproximação entre a teoria e prática, e dessa forma, tornando as aulas mais dinâmicas, atrativas e conferindo maior significação no processo de construção do conhecimento Geográfico. No ensino superior, a abordagem do conteúdo de solos associado ao uso de experiências práticas se mostra fundamental para apropriação dos conceitos e construção dos conhecimentos sobre a ciência do solo, pois os alunos da licenciatura poderão reproduzir tais atividades em sala de aula, contribuindo para um melhor aproveitamento do conteúdo de solos no ensino Fundamental e Médio, visto a necessidade de conscientização da população sobre a importância do solo para o ambiente e a sociedade.

Nesse contexto, o presente artigo tem como objetivo promover a experimentação com solos como recurso didático para a abordagem do conteúdo no componente curricular Geografia no ensino Fundamental e Médio, visando conferir maior significação na construção do conhecimento sobre os solos. O artigo está organizado da seguinte forma: uma introdução onde é feita apresentação do tema, uma revisão teórica, com os principais autores que abordam a temática do trabalho, uma seção com os resultados e discussões da experiência 
desenvolvida, a seção de considerações finais e, por último, as referências, com as obras utilizadas.

\section{A IMPORTÂNCIA DO ENSINO DOS SOLOS}

O solo é um recurso natural dinâmico, passível de ser degradado em virtude do seu uso inadequado nas diversas atividades desenvolvidas pelo ser humano, seja na construção de cidades ou sistemas de produção agrícolas. O manejo inadequado do solo pode levar a degradação e perda de toneladas de solos ao ano pelos processos de erosão, segundo Lima,

\footnotetext{
A degradação do solo é observada por meio de: redução da fertilidade natural e do conteúdo de matéria orgânica; erosão hídrica e eólica; compactação; contaminação por resíduos urbanos e industriais; alteração para obras civis (cortes e aterros); decapeamento para fins de exploração mineral; e a desertificação e arenização (2005, p. 383).
}

A degradação ambiental é um problema crescente em todo o mundo, tendo em vista a contínua intervenção do homem sobre os ambientes naturais, extrapolando a capacidade de resiliência e recomposição destes frente às agressões oriundas da exploração demasiada (Muggler et al., 2004). Segundo Lima (2005, p. 383-384), o estudo e disseminação de informações sobre o solo são fatores que contribuem para a construção da consciência ambiental, no entanto, evidencia que "a mera informação sobre o solo não permitirá que ele seja conservado, pois a degradação dos solos e dos ambientes naturais está relacionada a uma série de aspectos econômicos, políticos e culturais". Dessa forma, é visto que a conservação e manejo sustentável dos solos sofre influência de diversas esferas da sociedade, mesmo assim, "uma das contribuições para colocar estas preocupações no cotidiano da comunidade seria por meio da educação, promovendo a manifestação de uma consciência em relação ao solo, revisando e (re)construindo valores e atitudes”. Nessa concepção, Frasson e Werlang pontuam que,

O solo, assim como todos os elementos naturais do planeta deve ser visto como patrimônio coletivo e, portanto, conservado por todos. No entanto, preservar o meio ambiente, como ato de cidadania ainda não tem seu pleno desenvolvimento na sociedade. A falta de conhecimento diante deste aspecto exige que se desenvolva uma consciência ecológica, demandando, portanto, uma educação ambiental (2010, p. 97). 
Este cenário evidencia a necessidade de um ensino significativo que promova a construção de um conhecimento crítico sobre a importância e necessidade urgente de políticas públicas e práticas que possibilitem sua conservação. Nesse sentido,

\begin{abstract}
A Educação em Solos busca conscientizar as pessoas da importância do solo em sua vida. Nesse processo educativo, o solo é entendido como componente essencial do meio ambiente, essencial à vida, que deve ser conservado e protegido da degradação. A Educação em Solos tem como objetivo geral criar, desenvolver e consolidar a sensibilização de todos em relação ao solo e promover o interesse para sua conservação, uso e ocupação sustentáveis. Com a Educação em Solos, busca-se construir uma consciência pedológica que, por sua vez, possa resultar na ampliação da percepção e da consciência ambiental (MUGGLER; PINTO SOBRINHO; MACHADO, 2006, p. 736).
\end{abstract}

Diante disso, é visto que a formação da consciência sobre a importância dos solos é um passo importante para a ampliação da percepção ambiental, para Muggler, Pinto Sobrinho e Machado (2006), a abordagem pedológica apresenta quatro objetivos específicos, são eles: ampliar a compreensão do solo; sensibilizar de forma individual e coletiva sobre a degradação do solo; desenvolver a conscientização sobre a conservação do solo e; popularizar o conhecimento sobre o solo.

No ensino Fundamental, o ensino do solo tem início desde os anos iniciais, ainda no processo de alfabetização. Segundo Gonzales e Barros (2000, p. 41), nessa fase, o solo é trabalhado tanto no enfoque geológico, como edafológico, portanto, o "trabalho deve ser feito interrelacionado, para que a criança assimile os conteúdos pedológicos não desvinculados do conhecimento historicamente construído". Depreende-se a partir disso, a relevância que é dada ao processo de educação ambiental desde o ensino nos anos iniciais do ensino Fundamental. Na visão de Lima (2005, p. 384), a educação em solos no ensino Fundamental ainda deixa lacunas na formação do educando, e para o autor a "melhoria da qualidade do ensino de solos no Nível Fundamental poderia aumentar a consciência ambiental dos estudantes em relação a este recurso natural”, o que promoveria maior conscientização ambiental sobre as formas de uso e ocupação do solo.

No âmbito do ensino Médio, um quadro semelhante é observado, as lacunas na formação docente e ausência de materiais didáticos que possam ser utilizados em apoio ao ensino do solo, também apontam para uma baixa conscientização acerca deste recurso natural por parte dos educandos. Para Sousa e Matos (2012, p. 73), o solo "tem seu estudo pouco valorizado na maioria dos livros e apostilas perante o ensino Médio, e como consequência temos uma preocupação cada vez menor por parte dos educandos na compreensão de tal elemento". Para os autores, o educando do ensino Médio necessita ter conhecimento sobre a Campos, Marinho e Reinaldo, $2019 \quad$ ISSN 2594-9616 171 
formação do solo, seus usos e consequências decorrentes para o meio ambiente, no espaço rural e urbano. Nesse contexto, é visto que a Educação Básica apresenta quadros que impedem a promoção de uma aprendizagem efetiva em solos, realidade que aponta para a necessidade de se pensar estratégias didático-pedagógicas que permitam reverter esse quadro e promover uma apropriação significativa e em consonância com a realidade vivida pelo educando.

Na Educação Básica, Lima, Lima e Melo (2007b) apontam que o tema solo pode e deve ser abordado durante todo o curso Fundamental e Médio, em todas as matérias e disciplinas, de forma interdisciplinar, com diferentes graus de complexidade em acordo com o ciclo em que está sendo trabalhado, para tanto, fazendo usos de recursos diversos que favoreçam a construção do conhecimento a respeito da temática.

\section{O ENSINO DO SOLO NO ÂMBITO DA GEOGRAFIA}

O ensino de Geografia vem buscando novas práticas e linguagens que permitam a construção significativa do conhecimento geográfico, aproximando o educando do seu cotidiano e possibilitando a compreensão do espaço vivido. Porém uma das grandes dificuldades no ensino do componente é a dificuldade de abordagem dos conteúdos vistos como difíceis, em vista disso alguns conteúdos são priorizados em detrimentos de outros, ou por afinidade do professor, ou por lacunas na formação docente que o impedem de realizar aulas significativas sobre determinados conteúdos do currículo de Geografia no ensino Fundamental e Médio, dentre eles, o conteúdo de solos (FALCONI, 2004).

Para Sacramento e Falconi (2011, p. 2), são diversas as barreiras encontradas no ensino do solo, dentre elas a "dificuldade dos professores em trabalhar com essa temática" e o “excesso de conteúdos que precisam organizar". Resultando em aulas expositivas onde são apresentados conceitos descontextualizados da realidade do aluno, onde o professor poderia optar por recorrer às atividades práticas e possibilitar juntos com o educando a aproximação entre teoria e prática, conferindo maior significação à prática pedagógica. Diante dessa realidade, onde se diminui a importância do ensino do solo, as autoras, pontuam que,

\footnotetext{
Ao pensar na Geografia Escolar e na importância dessa temática dentro dos conteúdos, temos que levar em consideração a Educação Geográfica, sendo uma das possibilidades de se pensar um ensino voltado ao estímulo de ações que mobilizem o aluno a construção do conhecimento. Isso quer dizer que, pensar o ensino possibilita criar condições para que o aluno compreenda os fenômenos geográficos que ocorrem a sua volta (SACRAMENTO; FALCONI, 2011, p. 2).
} 
Segundo Lima, Lima e Melo (2007b), apesar de sua importância, o espaço dedicado ao solo, no ensino Fundamental e Médio, é frequentemente nulo ou relegado a um plano menor, tanto na área urbana como rural. Este conteúdo nos materiais didáticos, muitas vezes, está em desacordo com os Parâmetros Curriculares Nacionais (PCNs) e, frequentemente encontra-se desatualizado, incorreto ou fora da realidade dos solos brasileiros. Nesse sentido, destaca-se o livro didático, que em muitos casos é o único recurso didático disponível para o professor. $\mathrm{Na}$ maioria das vezes trazendo uma realidade que não aborda adequadamente o conteúdo de solo, trazendo informações incoerentes e superficiais, o que acaba sendo reproduzido pelo professor. Sobre o livro didático, Nunes, Azevedo e Silva, destacam que,

\begin{abstract}
O livro didático se constitui em um importante instrumento no processo de ensinoaprendizagem, facilitando a apropriação de conceitos por meio da linguagem escrita e imagética. Para o ensino de Geografia, sobretudo em escolas públicas, o livro didático torna-se um elemento de grande relevância por permitir o trabalho com diversas informações, como mapas, imagens, gráficos, tabelas, textos e exercícios. Entretanto, o livro não deve ser considerado o único recurso didático a ser utilizado, tendo em vista a necessidade de diversificar as práticas pedagógicas para dinamizar as aulas e favorecer a construção de conhecimentos pelos alunos (2016, p. 274).
\end{abstract}

Nessa conjuntura, o professor não deve balizar sua prática de ensino no uso exclusivo do livro didático, em vista que é necessário que este seja complementando por recursos diversificados, possibilitando assim, novas possibilidades para o ensino-aprendizagem. Experiências desenvolvidas por algumas universidades mostram que alunos e professores podem ser estimulados a explorar novos recursos no ensino-aprendizagem sobre a ciência do solo. Incluindo o solo dentro das preocupações ambientais da escola e, por extensão, da sociedade brasileira. Tais experiências desempenham a função de recurso didático, tornando as aulas mais atrativas e dinâmicas.

Segundo Castoldi e Polinarski (2009, p.685), “com a utilização de recursos didáticopedagógicos, pensa-se em preencher as lacunas que o ensino tradicional geralmente deixa, e com isso, além de expor o conteúdo de uma forma diferenciada, fazer dos alunos participantes do processo de aprendizagem", o que permite explorar novas possibilidades de aprendizagem em relação aos conteúdos ministrados.

Em relação aos educandos, Silva et al. (2017, p. 22), afirmam que os recursos didáticos devem servir "como motivação aos mesmos, predispor maior interesse pelo conteúdo ministrado e facilitar a compreensão do conteúdo proposto". No contexto do ensino dos solos, destaca-se as atividades pedagógicas e os recursos didáticos desenvolvidos pela Universidade Federal do Paraná no Projeto de Extensão Universitária Solo na Escola, no qual é 
disponibilizado uma série de atividades práticas com o solo que podem ser reproduzidas em sala de aula e utilizadas como recurso didático, são exemplos, o uso das frações granulométricas do solo, porosidade, consistência, plasticidade, densidade, capacidade de filtro, dentre outras. A realização de experiências como método de ensino, permite ao educando desenvolver uma posição ativa e crítica, fornecendo possibilidades para que construa seu próprio conhecimento. Segundo Goulart, Silva e Waber (2016), a realização de aulas práticas como estratégia de ensino, permite que o ensino do solo se torne mais efetivo, auxiliando na compreensão e construção dos conceitos, que muitas vezes é abstrato.

Diante dessa realidade, é visto que as feições morfológicas do solo podem ser utilizadas como recurso didático nas aulas de Geografia do ensino Fundamental e Médio como ferramenta de auxilio ao professor na promoção de aulas mais atrativas que permitam a construção de conhecimentos significativos sobre os solos, e viabilizem a conscientização da sua importância para a manutenção da vida, para o ambiente e para a formação cidadã. Estes são pontos chaves a que se propõe o ensino de Geografia ao analisar as formas de ocupação do espaço geográfico.

\section{MATERIAL E MÉTODOS}

As experiências práticas foram desenvolvidas em turmas do componente curricular Pedologia do curso de Licenciatura Plena em Geografia, da Universidade Estadual da Paraíba, Campus I, nos turnos manhã e noite, com um total de 42 alunos participantes. As turmas nas quais foram realizadas as experiências são do $6^{\circ}$ período do curso e eram iniciantes no componente. A realização dos experimentos teve como objetivo apresentar aos alunos conceitos básicos da ciência do solo e formas práticas de trabalhar os conteúdos de solo na Educação Básica, em vista que os participantes são estudantes de licenciatura em Geografia. A realização das atividades foi dividida em quatro momentos: aplicação prévia de questionários aos alunos visando compreender ao final a contribuição das atividades; apresentação expositiva dos principais conceitos sobre solo e sua importância para a manutenção da vida nos sistemas terrestres e aquáticos, bem como suas formas de uso e ocupação; realização dos experimentos e discussão; e por fim, reaplicação do questionário para fins de comparação acerca da aprendizagem sobre os solos.

Foram utilizados os seguintes materiais: amostras de solo argiloso, siltoso e arenoso, torrões de solo, lupa escolar, fita adesiva, folhas de papel ofício A4, coador de café, tesoura, fitas elásticas, 1 litro de água, 3 garrafas pets transparentes e copos descartáveis. Para 
realização dos experimentos em cada um dos turnos, cada turma foi separada em 3 grupos para facilitar a execução das atividades e acompanhamento do desenvolvimento dos experimentos. Ao todo, foram desenvolvidos 4 experimentos, estes foram obtidos na Experimentoteca de Solos da UFPR. São eles: porosidade do solo, textura do solo, consistência do solo e infiltração da água no solo. Abaixo segue a descrição dos experimentos.

Porosidade do solo: Cada grupo recebeu um torrão de solo e uma lupa para identificar os poros do solo e em seguida um copo com água para mergulhar o torrão e observar a saída das bolhas provocadas pelo ar presente nos poros do torrão.

Textura do solo: Foram distribuídos quatro copos descartáveis para cada grupo, contendo amostras de solo argiloso, siltoso e arenoso, com areia nas frações fina e grosseira. Foi entregue também, um quinto copo contendo pequenos papéis recortados com os nomes: areia fina, areia grossa, silte e argila, junto com uma fita adesiva. Neste experimento os alunos ficaram responsáveis por nomear cada amostra com base na textura apresentada pelas frações após manuseio com as mãos.

Consistência do solo: Após o experimento de textura, foi solicitado que cada grupo sentisse com as mãos a consistência apresentada por cada amostra, quando seca, úmida e complemente molhada, e medisse o grau de plasticidade e pegajosidade apresentada por cada amostra e quando possível sua resistência ao dobramento.

Infiltração da água no solo: Para realização do experimento de infiltração, foram cortadas duas garrafas pets ao meio, a parte inferior serviu como copo e a parte superior como funil, a parte superior foi tampada com papel coador de café, presa com elástico e colocada dentro da parte inferior da garrafa. Em seguida, foi colocada uma amostra de solo dentro de cada recipiente, sendo as amostras: arenosa e argilosa. Por fim, foi colocada a mesma quantidade de água em cada uma das amostras com o intuito de verificar a velocidade de infiltração e o armazenamento da água em cada uma delas.

Após a realização de todos os experimentos, foi feita a reaplicação do questionário, com o acréscimo de duas questões, seguido de discussão das principais questões levantadas pelos alunos, e também sobre as possibilidades de aplicabilidade das atividades práticas nas séries da Educação Básica. As respostas obtidas com o questionário foram utilizadas para compor a seção dos resultados e discussões deste trabalho, bem como para propor novas atividades e possibilidades de aprendizagem em solos. 


\section{RESULTADOS E DISCUSSÕES}

De início foi aplicado o questionário com os alunos, buscando verificar a compreensão prévia destes acerca da temática dos solos, dando ênfase aos conhecimentos referentes à origem, uso, ocupação e características morfológicas do solo. No passo seguinte, foi realizada uma exposição teórica, com auxílio de datashow, abordando os principais conceitos referentes à origem e formação do solo; propriedades físicas; características morfológicas; classificação; uso e ocupação; erosão e degradação dos solos e; conservação e conscientização ambiental. Durante a exposição, os pontos foram discutidos com os alunos buscando contextualizar as informações com o espaço vivido destes. Após o aporte teórico, deu-se sequência com a experimentação.

O primeiro experimento tratou da porosidade do solo (Figura 1). Segundo Silva (2014, p. 33) no solo "formam-se dois tipos de poros, os macroporos (poros com diâmetro maior que 0,05 mm) e os microporos (poros com diâmetro menor que 0,05 mm). Normalmente a água ocupa os microporos, e o ar ocupa os macroporos". Esse conjunto de poros compõe a chamada porosidade do solo.

Figura 1 - Torrões de solo utilizados na realização do experimento de porosidade.

\section{Fonte: Os autores (2018)}

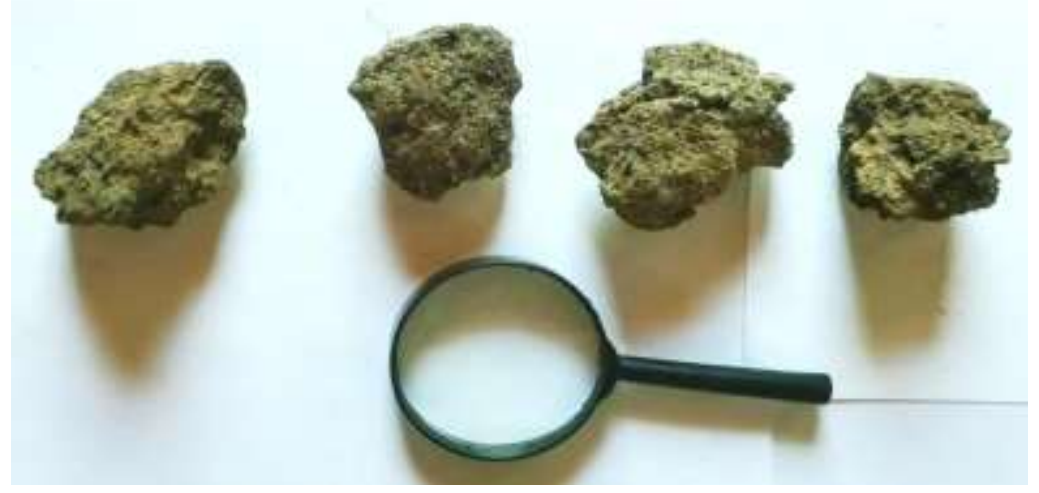

Para Lima (2014, p. 65), a porosidade é "importante para o armazenamento e movimento da solução do solo (fase líquida) e do ar do solo (fase gasosa) e para o desenvolvimento das raízes das plantas". Além disso, o autor aponta que no contexto escolar “deve ser claramente indicado aos alunos que as raízes crescem ocupando o espaço poroso do solo, e não "comendo" a fração sólida (minerais e matéria orgânica)". Pois assim, são fornecidos subsídios ao aluno para a compreensão das funções desempenhadas pelos poros do solo, alertando que manejos inadequados podem promover a compactação do solo e atuar na 
“redução da porosidade, diminuindo a infiltração de água e penetração de oxigênio", condição que afeta diretamente a qualidade do solo.

Nesse sentido, observado o desempenho dos alunos na realização das atividades e respostas apresentadas nos questionários, depreende-se que este experimento permitiu aos alunos perceber a presença de poros e do ar no solo, sua importância para manutenção dos organismos e das plantas, bem como sua influência na infiltração e armazenamento da água. O segundo experimento realizado teve com base a textura do solo (Figura 2). De acordo com Lima (2014, p. 62), a textura do solo "refere-se à proporção relativa das frações areia, silte, e argila em um solo" e "para determinar a textura, de modo simples, deve-se sentir a sensação ao tato, ao molhar uma amostra de solo e esfregar com força entre o polegar e o indicador". Tais procedimentos podem ser realizados na sala de aula ou mesmo em aulas de campo, em virtude da facilidade e possibilidade de experimentação de amostradas variadas no campo.

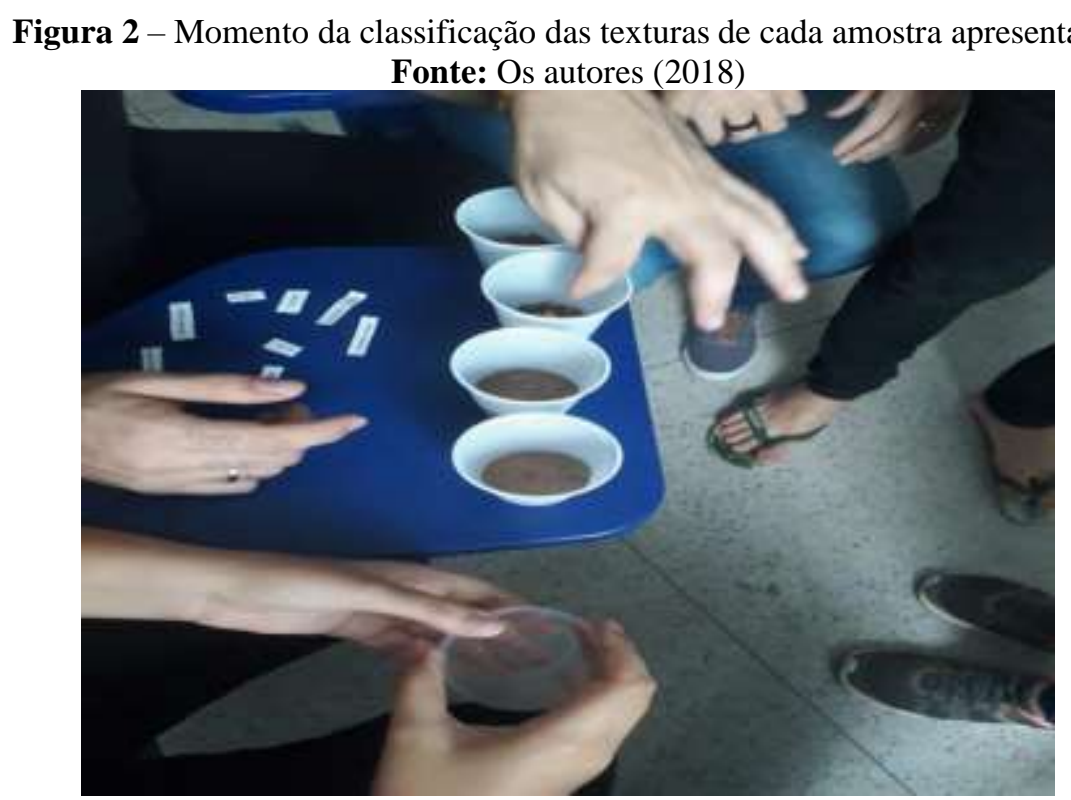

Diante das exposições orais dos alunos e análise das repostas do questionário, pontuase que o experimento levou os alunos à compreensão do conceito de textura do solo, fornecendo bases para o entendimento de sua variação e diferenciação, a partir do teste de textura com as mãos. Possibilitando que os mesmos reconheçam e identifiquem as frações granulométricas do solo em ambiente natural, e apontem as particularidades de conservação apresentadas pelas diferentes texturas, em se tratando do manejo, fragilidade e susceptibilidade a processos de erosão. Lima et al. (2015, p.184) após realizarem a experiência de textura do solo com alunos de ensino Superior e alunos do ensino Fundamental, observaram que os dois públicos apresentaram aprendizagem semelhantes e 
demonstraram "compreensão de que os solos apresentam diferentes características e formações diferentes, podendo um ser mais propício ao desenvolvimento de determinados cultivos em relação a outro".

Diante dos resultados observados após a realização do experimento verifica-se a importância e a contribuição dessa prática ao ensino do solo nas aulas de Geografia, visto que o procedimento fornece subsídios para uma aprendizagem significativa em relação à textura das amostras utilizadas e as características apresentadas pelos solos.

Após o experimento de textura, foram utilizadas as mesmas amostras de solo para realização da prática de consistência do solo (Figura 3). A consistência do solo pode ser entendia como a resistência apresentada pelo solo à deformação ou ruptura, ou mesmo o grau de adesão/coesão apresentada pela amostra. Como aponta Lima (2014, p. 61-62), "a expressão da consistência quando o solo está seco é a dureza, que é a resistência à ruptura dos torrões", já “a plasticidade é observada quando o material do solo, no estado molhado, ao ser manipulado, pode ser modelado constituindo diferentes formas", outra propriedade apresentada pelo solo é a pegajosidade, "refere-se à aderência do solo às mãos ou a outros objetos, quando molhado". Este último atributo é utilizado como base para a escolha de usos e ocupações do solo, tendo em vista que uma elevada pegajosidade apresenta limitações de manejo.

Figura 3 - Mensuração da consistência do solo molhado.

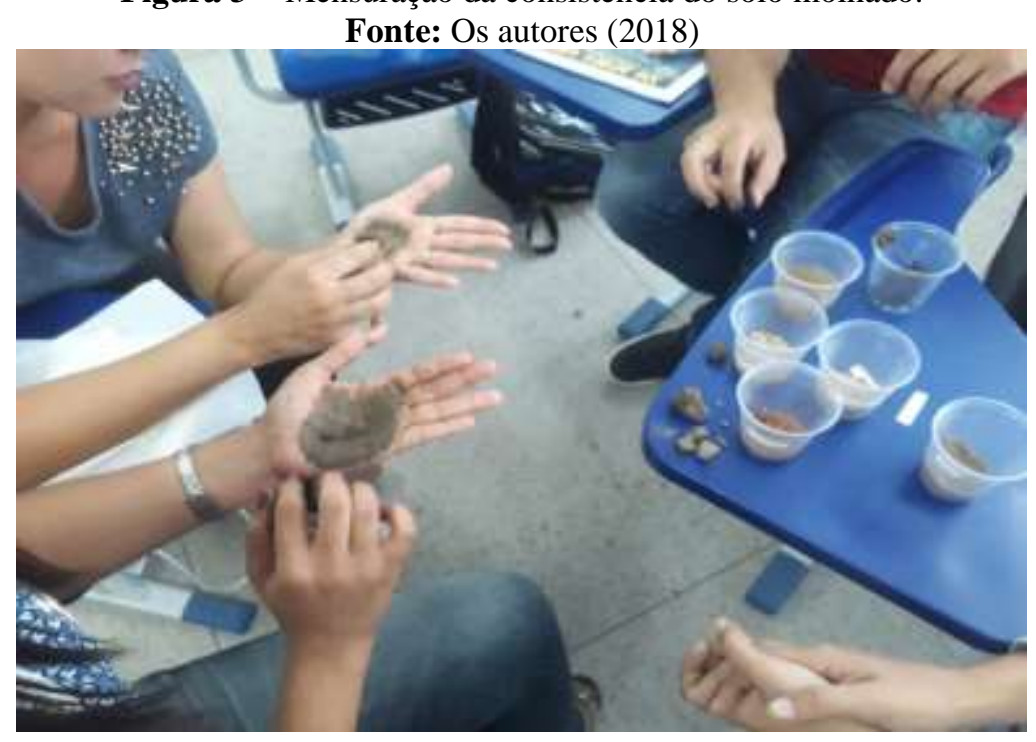

O experimento possibilitou aos alunos compreender que a consistência varia de acordo com a composição do solo e as frações granulométricas nele predominantes, fornecendo bases para práticas simples e eficientes de análise da consistência com o tato. Além disso, permitiu 
diferenciar plasticidade e pegajosidade, e apontar as limitações e as possibilidades apresentadas pela consistência do solo no manejo de sistemas urbanos e agrícolas. Tal aprendizado foi verificado pelo desempenho dos alunos na realização do experimento e análise do questionário aplicado após a conclusão das atividades.

O último experimento, infiltração da água no solo, foi realizado de forma coletiva, e executado com a participação de todos os grupos (Figura 4). No processo de infiltração a água adentra pelos poros e canais em direção ao lençol freático, rios e lagos, aflorando nas áreas mais baixas do relevo (MELO; LIMA, 2007). Favaretto e Dieckow (2007, p. 112) explicam que parte da água que chega à superfície do solo "irá infiltrar nele, através de poros e canais. Parte dessa água será absorvida pelas raízes, garantindo a sobrevivência das plantas, enquanto parte continuará descendo através do perfil do solo e irá abastecer os depósitos subterrâneos de água”. O processo é influenciado diretamente por fatores como textura e composição do solo, que podem aumentar ou atenuar o processo durante eventos de precipitação, o processo também é influenciado pelo tipo de solo e quadro de manejo empregado.

Figura 4 - Experimento para percepção da velocidade de infiltração da água nas amostras de solo arenoso e argiloso. Fonte: Os autores (2018).

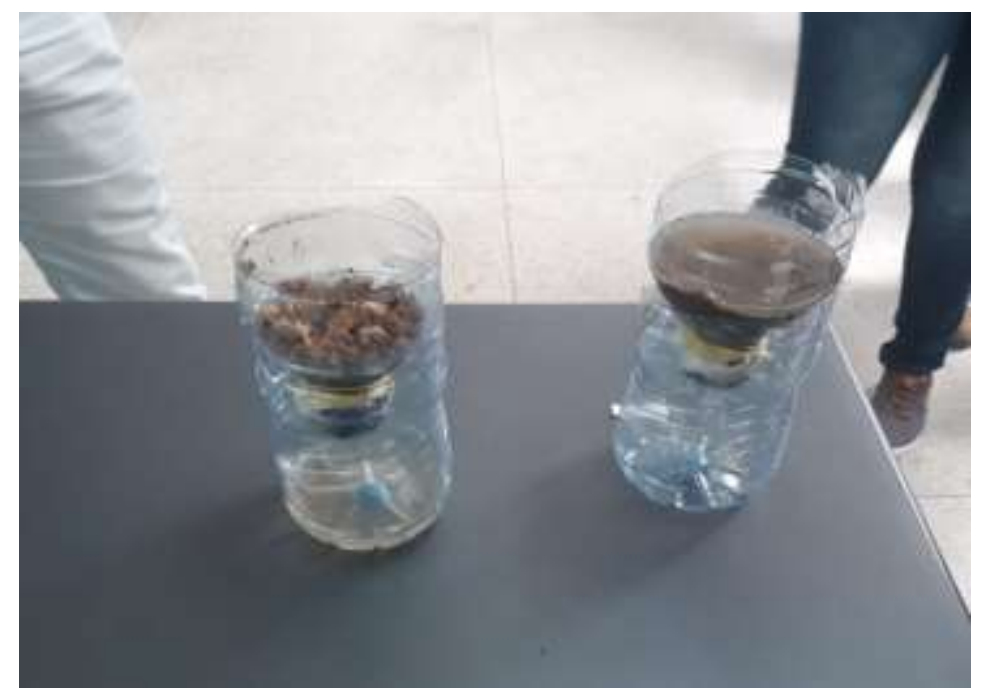

Em solos arenosos, por exemplo, em vista da "grande capacidade de infiltração e baixo poder de retenção de poluentes, o lençol freático pode ser facilmente contaminado por fertilizantes, agrotóxicos, e poluentes urbanos ou industriais" (LIMA; LIMA; MELO, 2007a, p. 80). Nesse sentido, compreender o comportamento apresentado pelos solos durante infiltração, principalmente a partir dos eventos de precipitação, é de fundamental importância para se pensar formas adequadas de usos, ocupação e planejamentos para fins manejo e conservação. Cunha et al. (2013, p.79), ao realizarem experimento semelhante em escolas 
públicas de ensino Fundamental na cidade de Marechal Cândido Rondon - PR, verificam que “os ensaios de infiltração e retenção de água no solo, realizados a partir de amostras de solos argilosos e arenosos, permitiu que os alunos percebessem como a composição dos mesmos influencia na capacidade de infiltração e retenção de água”. Do mesmo modo, os alunos ao realizem este experimento puderam perceber que a velocidade de infiltração e o armazenamento da água no solo é um processo que sofre influência da composição do solo, da porosidade, da textura e consistência.

Durante o experimento foi explicado aos alunos que diferentes manejos e formas de ocupação do solo influenciam diretamente na capacidade de infiltração e armazenamento da água no solo, podendo seu manejo vir a intensificar processos de erosão e assoreamentos de corpos hídricos em áreas próximas. Nesse sentido, verifica-se a importância da simulação do processo de infiltração para a construção do conhecimento em solos, em via para a conscientização ambiental.

A análise do questionário aplicado antes da exposição teórica (Quadro 1), mostrou que os alunos possuíam conhecimentos superficiais sobre o conteúdo, mais especificamente sobre sua importância para o meio ambiente. Além disso, apresentaram amplo conhecimento sobre as formas de uso e ocupação do solo na atualidade, no entanto, apresentaram conhecimento relativamente vago quanto à formação e a morfologia do solo. As respostas obtidas relacionam-se ao fato de os alunos ainda não terem tido contato com conteúdos relacionados à gênese e as propriedades morfológicas dos solos, de modo que, no componente curricular Pedologia, se deu o primeiro contato das turmas com a temática.

Quadro 1 - Questionário aplicado nas turmas de Pedologia. Fonte: Os autores (2018).

1. Como ocorre a formação do solo?

\section{QUESTÕES}

2. Quais são os principais tipos de uso e ocupação do solo na atualidade?

3. O que é a morfologia do solo? Quais são as principais frações granulométricas do solo?

4. Qual textura do solo permite maior velocidade de infiltração da água?

5. O que é a consistência e como ela interfere no manejo do solo?

6. O que são macro e microporos e quais suas funções no solo?

8. Qual a importância do solo para o meio ambiente?

9. Os experimentos contribuíram para o seu aprendizado em solos? Justifique.

10. Em sua opinião os experimentos podem ser aplicados em turmas de ensino Fundamental e Médio? Aponte sugestões.

No questionário aplicado após a realização dos experimentos, foram acrescentadas as questões 9 e 10 (Quando 1), visando analisar a visão dos alunos como futuros professores em 
relação a aprendizagem e a contribuição dos experimentos para a construção dos conhecimentos teóricos e técnicos sobre os solos. As respostas obtidas nos questionários aplicados após a realização dos 4 experimentos foram mais claras e objetivas, em todas as questões, evidenciando assim, a contribuição do conjunto desenvolvido: exposição teórica e aplicação prática.

As respostas apresentadas para a questão 9 foram semelhantes para os dois turnos, manhã e noite, e de forma geral, mostraram que os experimentos práticos contribuíram de forma positiva para a construção conhecimento, já na questão 10, ficou evidente que na opinião dos alunos, os mesmos experimentos podem ser reproduzidos na Educação Básica, variando apenas o grau de dificuldade conforme a série e faixa etária dos alunos. Segue abaixo as respostas apresentadas por dois alunos dos dois turnos para a pergunta 9: Os experimentos contribuíram para o seu aprendizado em solos? Justifique. Respostas:

Sim, os experimentos possibilitaram compreender com maior lucidez a textura do solo, o processo de infiltração e como cada textura reage a tal processo (ALUNO 1, MANHÃ).

Sim, pois em contato com o solo aprendemos a diferenciar e caracterizar os diferentes tipos, além disso, posso utilizar os mesmos experimentos para desenvolver atividades com meus alunos. (ALUNO 2, NOTURNO).

Sacramento e Falconi (2011) ressaltam que as ações teórico-metodológicas no âmbito da Geografia devem ser pensadas de modo que forneçam aportes para a formação de uma consciência da espacialidade dos fenômenos vivenciados ao longo da trajetória de vida do sujeito, oportunizando a construção de uma organização lógica do seu conhecimento. Nesse contexto, é visto a contribuição da associação da exposição teórica associada com os experimentos de solos para o desenvolvimento da aprendizagem. O que também corroborou estes como importantes recursos didáticos que podem auxiliar e conferir maior significação no processo de ensino-aprendizagem do componente curricular Geografia. Como é visto na resposta do aluno do turno noturno, o contato com as amostras permitiu ao aluno aprender a diferenciar as frações granulométricas e as principais características ambientais desses solos.

Goulart, Silva e Waber (2016), desenvolvendo atividades práticas no ensino do solos, em escola pública no município de São Gabriel - RS, também verificaram resultados semelhantes, e constataram as contribuições dos experimentos para a aprendizagem em solos. Observados os resultados, os autores apontam a experimentação como método de ensino eficiente, uma vez que fornece subsídios para que o aluno desenvolva uma postura ativa e crítica, desse modo, possibilitando que ele construa seu próprio conhecimento. 
Nesse sentido, os experimentos se mostram eficientes para a construção dos principais conceitos, além de promover o contato do aluno com o solo, permitindo a construção de um conhecimento significativo em solos, o que reflete diretamente no processo de conscientização sobre a importância destes para o meio ambiente e para manutenção das atividades humanas. Em relação a isso, Mendes (2017, p. 53) destaca que no mesmo grau de importância que há em se compreender os componentes que permitem a formação e desgaste dos solos indica-se também "a importância de, ao ensinar esse conteúdo, evidenciar as questões sociais inerentes a esse componente físico-natural do espaço geográfico". Nessa perspectiva, no ensino de Geografia é fundamental que o professor busque abordar os conteúdos como partes integrantes de um todo, o espaço geográfico. Facilitando assim, a apropriação dos conceitos e contextualização dos conteúdos.

Como ressaltam Muggler et al. (2004, p. 2), o ensino do solo nos espaços formais e informais de educação "é uma maneira de oportunizar a conscientização ambiental das pessoas", promovendo uma educação significativa, "de forma que elas tenham um conjunto de valores de base que as instrumentalize para perceber, analisar e avaliar os impactos das ações públicas e privadas sobre o solo e o meio ambiente, assim como o impacto de suas próprias ações". Diante disso, "reforça-se a necessidade de se promover, por meio da educação, a manifestação de uma "consciência pedológica", onde valores e atitudes precisam ser revistos e (re)construídos". No contexto escolar, então, se faz necessário sua abordagem em todas as etapas da Educação Básica, ultrapassando a visão do solo como um componente isolado do ambiente, mas como integrante de um todo, que em conjunto com os demais componentes ambientais, torna-se imprescindível para o funcionamento dos sistemas terrestres. Tal abordagem nos espaços escolares abre um leque de possibilidades para a discussão dos quadros de degradação dos solos e as práticas de conservação na atualidade.

Para Muggler, Pinto Sobrinho e Machado (2006, p.735), a relação do homem com a natureza nas sociedades modernas desenvolve-se a partir da concepção da natureza como uma dávida, provedora de recursos, disponível para o uso da humanidade. Nessa conjuntura, a degradação do solo aparece como resultado dessa concepção de usufruto da natureza que se contrapõe à sustentabilidade dos recursos naturais. Na visão dos autores, é fundamental, diante desse cenário, “desenvolver e fomentar a sensibilização das pessoas, individual e coletivamente, em relação ao solo, no âmbito de uma concepção que considere o princípio da sustentabilidade, na qual valores e atitudes de desvalorização do solo possam ser revistos". Evidencia-se a partir disso, as discussões em torno da conservação do solo, que segundo 
Favaretto e Dieckow (2007), referem-se à combinação de métodos e estratégias de manejo e uso da terra que promovem a proteção do solo contra seu esgotamento físico, químico e biológico. Permitindo sua conservação e uso sustentável, como meio de garantir sua disponibilidade para as gerações futuras.

Diante do exposto, é visto a necessidade de se pensar novos aportes teóricos e metodológicos que proporcionem novas abordagens do conteúdo de solos na Educação Básica, buscando assegurar a construção de um conhecimento crítico, que possibilite ao educando compreender as propriedades e funções deste recurso natural no ambiente, e assim, atente para a compreensão de meios que permitam seu uso sustentável. Sacramento (2010, p. 8), então, evidencia que "ensinar geografia é permitir que o aluno compreenda as transformações dos fenômenos geográficos que interferem no modo de vida não só do aluno, mas da sociedade na qual ele vive". Corrobora-se assim, a importância do ensino do solo nas aulas de Geografia e reafirma-se a necessidade de uma prática de ensino contextualizada com o espaço vivido do aluno, que promova a conscientização ambiental, o pensando crítico e o desenvolvimento de novas metodologias que venham a agregar nas estruturas do processo de ensino-aprendizagem dos solos na Educação Básica.

\section{CONSIDERAÇÕES}

Os resultados evidenciaram os experimentos com solo como importantes recursos facilitadores da aprendizagem, pois promoveram a construção de conhecimentos sobre as propriedades, características e feições morfológicas dos solos. Conhecimentos fundamentais para a compreensão do solo com um recurso natural finito, integrante do ambiente e indispensável para a manutenção dos ecossistemas. Os experimentos assim, apontaram para necessidade de se pensar sobre as formas de uso e ocupação do solo na atualidade e como as formas de manejo têm influenciado na degradação do ambiente. Reflexões fundamentais no âmbito do ensino de Geografia, uma vez que o mesmo se alicerça na promoção de subsídios teórico-metodológicos para a formação do sujeito e seu exercício cidadão.

Ressalta-se assim, a importância da formulação de novas linguagens, práticas de ensino, estratégias didáticas e recursos didáticos para o ensino do solo, não só na Geografia, como nas demais áreas do conhecimento. Os recursos didáticos, sendo os mais comuns, assim como visto, cumprem a função de promover o diálogo e a interação, facilitando assim a apropriação dos conceitos abordados, evidenciando-se nesse sentido, importantes ferramentas facilitadoras da aprendizagem. Os experimentos práticos se mostraram adequados e efetivos 
para o ensino, desde que associados a um planejamento que busque contemplar a teoria com os conhecimentos práticos, possibilitando assim, uma aprendizagem mais significativa para a realidade do educando.

\section{REFERÊNCIAS}

CASTOLDI, R.; POLINARSKI, C. A. A Utilização de Recursos Didático-Pedagógicos na Motivação da Aprendizagem. In: SIMPÓSIO NACIONAL DE ENSINO DE CIÊNCIA E TECNOLOGIA,I, 2009, Ponta Grossa - PR. Anais do I Simpósio Nacional de Ensino de Ciência e Tecnologia - SINECT, Ponta Grossa - PR: UTFPR, 2009, p. 684-692. Disponível em: https://atividadeparaeducacaoespecial.com/wp-content/uploads/2014/09/recursosdidatico-pedag\%C3\%B3gicos.pdf. Acesso em: 20 de nov. de 2018.

CUNHA, J. E.; ROCHA, A. S.; TIZ, G. J. MARTINS, V. M. Práticas pedagógicas para ensino sobre solos: aplicação à preservação ambiental. TERR/E DIDATICA, v. 9, n.2, p.7481, 2013. Disponível em: https://periodicos.sbu.unicamp.br/ojs/index.php/td/article/view/8637395. Acesso em: 20 out. 2018.

FALCONI, S. Produção de material didático para o ensino de solos. 2004. 115 f.

Dissertação (mestrado) - Universidade Estadual Paulista, Instituto de Geociências e Ciências Exatas, 2004. Disponível em: http://hdl.handle.net/11449/95637. Acesso em: 21 nov. 2018.

FAVARETTO, N.; DIECKOW, J. Conservação dos recursos naturais solo e água. In: LIMA, V.C.; LIMA, M. R.; MELO, V.F. (ed.). O solo no meio ambiente: abordagem para professores do ensino fundamental e médio e alunos do ensino promov. Curitiba: Universidade Federal do Paraná, Departamento de Solos e Engenharia Agrícola, 2007. 130 p.

FONTES, L. E. F.; MUGGLER, C. C. Educação não formal em solos e o meio ambiente: desafios na virada do milênio. In: CONGRESO LATINOAMERICANO DE LA CIENCIA DEL SUELO, 14, 1999, Pucón (Chile). Resumenes. Temuco: Universidad de la Frontera, 1999. p. 833.

FRASSON, V. R.; WERLANG, M. K. Ensino de Solos na Perspectiva da Educação Ambiental: Contribuições da Ciência Geográfica. Geografia: Ensino \& Pesquisa, Santa Maria, v. 1 4, n. 1, p. 94- 99, 2010. Disponível em: https://www.passeidireto.com/arquivo/25153646/ensino-de-solos-na-pespectiva-da-educacaoambiental-contribuicoes-da-ciencia-geografica1. Acesso em 21 out. 2018.

GONZALES, S. L. M.; BARROS, O. N. F. O ensino de pedologia no ciclo básico de alfabetização. Geografia, Londrina, v. 9, n. 1, p. 41-49, jan./jun. 2000. Disponível em: http://www.uel.br/revistas/uel/index.php/geografia/article/view/10174. Acesso em: 12 nov. 2018.

GOULART, A. V.; SILVA, C. C. F.; WABER, M. A. Importância das aulas práticas no ensino de solos. In: SALÃO INTERNACIONAL DE ENSINO, PESQUISA E EXTENSÃO, 8, 2016, Uruguaiana - RS. Anais do $8^{\circ}$ Salão Internacional de Ensino, Pesquisa e Extensão, Uruguaiana - RS: Unipampa, 2016, p. 1-2. Disponível em: 
http://publicase.unipampa.edu.br/index.php/siepe/article/view/19281. Acesso em: 15 nov. 2018.

LIMA, G. A. C; ARAÚJO, P. M; REINALDO, L. R. L. R; XAVIER, R. A. Textura do Solo: Importância da Realização de Atividades Práticas no Ensino de Geografia. Revista Tamoios, São Gonçalo (RJ), ano 11, n. 2, págs. 177-188, jul/dez. 2015. Disponível em: https://www.epublicacoes.uerj.br/index.php/tamoios/article/view/15318. Acesso em: 20 nov. 2018.

LIMA, J. S.; ANDRADE, S. F.; FORTUNA, D. S. Pedologia aplicada à Geografia: desafios e perspectivas na educação básica. Caderno de Estudos Geoambientais - CADEGEO, v.07, n.01, p.05-20, 2016. Disponível em:

http://www.cadegeo.uff.br/index.php/cadegeo/article/download/42/24. Acesso em: 10 nov. 2018 .

LIMA, M. R. O solo no ensino de ciências no nível fundamental. Ciência \& Educação, v. 11, n. 3, p. 383-395, 2005. Disponível em:

http://www.escola.agrarias.ufpr.br/arquivospdf/Soloensinociencias.pdf. Acesso em: $10 \mathrm{dez}$. 2018.

LIMA, M. R. Perfil e morfologia do solo. In: LIMA, M. R. (org.). Conhecendo os solos: abordagem para educadores do ensino fundamental na modalidade à distância. Curitiba: Universidade Federal do Paraná, Departamento de Solos e Engenharia Agrícola, 2014. 167p.

LIMA, V. C. LIMA, M. R., MELO, V. F. Classificação brasileira de solos. In: LIMA, V.C.; LIMA, M.R.; MELO, V.F. (ed.). O solo no meio ambiente: abordagem para professores do ensino fundamental e médio e alunos do ensino médio. Curitiba: Universidade Federal do Paraná, Departamento de Solos e Engenharia Agrícola, 2007a. 130 p.

LIMA, V.C.; LIMA, M.R.; MELO, V.F. (ed.). O solo no meio ambiente: abordagem para professores do ensino fundamental e médio e alunos do ensino médio. Curitiba: Universidade Federal do Paraná, Departamento de Solos e Engenharia Agrícola, 2007b. 130 p.

MELO, V. F.; LIMA, VC. Composição do solo, crescimento de plantas e poluição ambiental. In: LIMA, V.C.; LIMA, M.R.; MELO, V.F. (ed.). O solo no meio ambiente: abordagem para professores do ensino fundamental e médio e alunos do ensino médio. Curitiba: Universidade Federal do Paraná, Departamento de Solos e Engenharia Agrícola, 2007. 130 p.

MENDES, S. O. O solo no ensino de Geografia e sua importância para a formação cidadã na educação básica. 2017. 160 f. Dissertação (Mestrado em Geografia) Universidade Federal de Goiás, Goiânia, 2017.

MUGGLER, C. C.; PINTO SOBRINHO, F. A.; MACHADO, V. A. Educação em Solos: princípios, teoria e métodos. R. Bras. Ci. Solo, v. 30, n.4, p.733-740, 2006. Disponível em: http://www.scielo.br/scielo.php?pid=S0100-

06832006000400014\&script=sci_abstract\&tlng=pt. Acesso em: 15 nov. 2018.

MUGGLER, C. C.; PINTO SOBRINHO; F. A.; CIRINO, F. O.; SANTOS, J. A..; COSTA, C. A. Capacitação de professores do Ensino Fundamental e médio em conteúdos e métodos em solos e meio ambiente. In: CONGRESSO BRASILEIRO DE EXTENSÃO 
UNIVERSITÁRIA, 2, Belo Horizonte, 2004. Anais. Belo Horizonte: Fórum de Pró Reitores de Extensão das Universidades Públicas Brasileiras, 2004. Disponível em: https://www.ufmg.br/congrext/Meio/Meio51.pdf. Acesso em: 10 dez. 2018.

NUNES, M. S.; AZEVEDO, R. J. G.; SILVA, P. E. A. B. A abordagem de conteúdos relativos à ciência dos solos em livros didáticos de geografia para o ensino médio. Revista de Geografia - PPGEO - UFJF, v.6, n.3, p.271-281, 2016. Disponível em: https://periodicos.ufjf.br/index.php/geografia/article/view/18031. Acesso em: 12 dez. 2018.

SACRAMENTO, A. C. R. Didática e Educação Geográfica: algumas notas. UniPluri/Versidad, Medellín, Col. v.10, n. 3, p. 1-9, 2010. Disponível em < http://aprendeenlinea.udea.edu.co/revistas/index.php/unip/issue/current> Acesso em: 20 out. 2018.

SACRAMENTO, A. C. R.; FALCONI, S. Educação Geográfica e Ensino de Solos: uma experiência em sala de aula. Revista Geográfica de América Central, Número Especial, EGAL, p. 1-15, 2011. Disponível em: https://core.ac.uk/download/pdf/48869437.pdf. Acesso em: 08 dez. 2018.

SILVA, A. C. M.; FREITAG, I. H.; TOMASELLI, M. V. F. BARBOSA, C. P. A importância dos recursos didáticos para o processo ensino-aprendizagem. Arquivos do MUDI, v 21, n 02, p. 20-31, 2017. Disponível em:

<http://periodicos.uem.br/ojs/index.php/ArqMudi/article/view/38176>. Acesso em: 22 out. 2018.

SOUZA, H. F. T.; MATOS, F. S. O Ensino dos Solos no Ensino Médio: desafios e possibilidades na perspectiva dos docentes. Geosaberes, Fortaleza, v. 3, n. 6, p. 71-78, jul. / dez. 2012. Disponível em: https://dialnet.unirioja.es/descarga/articulo/5547990.pdf. Acesso em: 18 dez. 2018. 